\title{
SELECTIVE CONTROL OF CALCIUM CARBONATE CRYSTALS MORPHOLOGIES USING SULFONATED POLYMER AS ADDITIVE
}

\author{
ANDRÓNICO NEIRA-CARRILLO*1, SAJU PILLAI ${ }^{2}$, RANJITH KRISHNA PAI ${ }^{3}$ \\ ${ }^{I}$ Faculty of Veterinary and Animal Sciences, University of Chile \\ ${ }^{2}$ Materials Science and Technology Division, CSIR-National Institute for Interdisciplinary Science and Technology (NIIST), \\ Industrial Estate P.O., Thiruvananthapuram, Kerala, India \\ ${ }^{3}$ Center for Nano and Materials Sciences, Jain University, Jain Global Campus, Kanakapura Road, Ramanagaram, Bangalore, India - 562112
}

(Received: May 29, 2013 - Accepted: December 9, 2013)

\begin{abstract}
We report two selective morphologies of $\mathrm{CaCO}_{3}$ crystals using poly(potassium 2-acrylamido-2-methylpropanesulfonate) [poly(KAMPS)] as template through gas diffusion method. The presence of anionic sulphonte groups on poly(KAMPS) determined the kinetic crystallization and was fundamental for stabilizing oriented triangle and tubular shape of calcite. The modified $\mathrm{CaCO}_{3}$ were followed by SEM and XRD techniques. Inorganic architectures with hierarchically complex shape and optimized properties have great potential as agents in optical, electronic, magnetic and biomedical applications.
\end{abstract}

Keywords: calcite, crystallization, gas diffusion method, polymorphs.

\section{INTRODUCTION}

Along the evolution, the living organisms have developed capacities to form intricate hybrid materials (biominerals) highly optimized through a complex mineralizing process called biomineralization ${ }^{(1-6)}$. For example, certain bacteria produce magnetic nanocrystals, many mollusks build $\mathrm{CaCO}_{3}$ shells, and mammals form bone and teeth, etc ${ }^{(7-9)}$. These biominerals often have remarkable mechanical, optical and magnetic properties related to the precise hierarchical assembly of nanoscale building blocks, formed at ambient temperature ${ }^{(10,11)}$. Therefore, the biominerals with defined microstructure consisting from mineral and organic parts, subdivided into the soluble and insoluble fraction ${ }^{(1-6,12,13)}$. The mineral generally contain a small amount of organic material, which is thought to provide a structural framework and to play an important roles in nucleation and regulation morphology and direction of crystal growth ${ }^{(1-6,13-15)}$.

In this communication, the use of sulphonated poly(KAMPS) was presented as good functionalization strategy for controlling the selectively of $\mathrm{CaCO}_{3}$ crystals morphology. We have demonstrated that the spatial arrangement of sulphonic groups attached to poly(KAMPS) can alter the nucleation and morphology of $\mathrm{CaCO}_{3}$ and the poly(KAMPS) can effectively induce oriented triangle crystals and tubular shape of calcite. The modified $\mathrm{CaCO}_{3}$ were followed by SEM and XRD techniques. This communication tried to highlights how functionalized polymers provide viable approach for studying various aspect of biomineralization such as shape, morphologies and production of the unstable polymorphs of $\mathrm{CaCO}_{3}$.

\section{MATERIALS AND METHODS}

\section{Materials}

All reagents and solvents were of the highest available grade. Calcium chloride, ethanol, sodium hydroxide (Analytic) and tris(hydroxymethyl) aminomethane (TRIS) were obtained from ACS-Merck; ammonium hydrogen carbonate $\left(\mathrm{NH}_{4} \mathrm{HCO}_{3}\right)$ was from J.T. Baker and methylene chloride $\left(\mathrm{CH}_{2} \mathrm{Cl}_{2}-\right.$ $\square 99.5 \%)$ from Sigma-Aldrich. The distilled water was obtained from capsule filter $0.2 \mu \mathrm{m}$ flow (U.S. Filter). Methylene chloride was purified by refluxing over lithium aluminum hydride (Aldrich- $95 \%$ pellets particle size 10x6 mm) for $72 \mathrm{~h}$ and distilled under argon. AMPS (Aldrich Chemicals) were used without further purification. The potassium salt of AMPS was prepared by dissolving $50 \mathrm{~g}$ of AMPS in $145 \mathrm{~mL}$ of milli-QTM water, with the subsequent addition of $27.8 \mathrm{~g}$ of $\mathrm{KOH}$, with cooling and constant stirring. The solution was titrated with KOHaq $(1000 \mathrm{~mol} / \mathrm{m} 3)$ to $\mathrm{pH}$ 7. The total solid content of the KAMPS/ water precursor material was $58.5 \mathrm{wt}-\%$. The polymer initiator, $4,4^{\prime}$-Azobis (4-cyanovaleric acid); ACVA (APS; Merck), and paraffin oil (Merck) were used as received. The chemical formulae for the poly(KAMPS) synthesized and studied are presented in Scheme 1. Synthesis
of
Poly(potassium
2-acrylamido-2-

2. methylpropanesulfonate)
Homopolymers of poly(potassium 2-acrylamido-2methylpropanesulfonate), poly(KAMPS), were synthesized with free-radical suspension-polymerization using a ACVA as initiator (Scheme 1). The monomers KAMPS $(15 \mathrm{~g})$ and the initiator ACVA $(0.0063 \mathrm{~g})$ were dissolved in $22.5 \mathrm{~mL}$ of milli-QTM water. After the solution had been purged with nitrogen gas for $30 \mathrm{~min}$, the mixture was transferred to a funnel. A suspending agent, polyvinyl alcohol (PVA; $0.6 \mathrm{~g}$ ) was added to paraffin oil $(69.6 \mathrm{~mL})$ in a roundbottomed flask with three necks. The PVA solution in paraffin oil was kept at a temperature of $70{ }^{\circ} \mathrm{C}$ and the aqueous solution of the monomers was added dropwise with stirring. The polymerization reaction was allowed to proceed for $4 \mathrm{~h}$, after which the reaction vessel was cooled to room temperature and the polymer material was retrieved by filtration and precipitation with acetone. The polymeric material was washed in milli-QTM water and precipitated twice with acetone, and then dried under vacuum at a temperature of $50{ }^{\circ} \mathrm{C}$. The KAMPS moiety in the homopolymer was identified by ${ }^{13} \mathrm{C}$ nuclear magnetic resonance (NMR) spectroscopy and was in good agreement with that of the added monomer.

3. In vitro $\mathrm{CaCO}_{3}$ crystallization

Crystallization experiments were carried out in the presence of poly(KAMPS) as additive and compared with a solution without polymer as blank control using the gas diffusion (GD) method. The GD method was performed as we described in previous works ${ }^{(16-20)}$. All experiments were carried out inside the Petri dish using of poly(KAMPS) at different $\mathrm{pH}$ values from $\mathrm{pH} 7$ to 12 at $1.0 \mathrm{mg} / \mathrm{mL}$ at $20^{\circ} \mathrm{C}$ for $24 \mathrm{~h}$. For these experiments a stock solution of $1.6 \mathrm{mg}$ of poly(KAMPS) in deionized water at different $\mathrm{pH}$ prepared as mother solution in an Eppendorf tube. $\mathrm{CaCO}_{3}$ results from the diffusion of $\mathrm{CO}_{2}$ into the buffered $\mathrm{CaCl}_{2}$ solution. The microbridges with the $\mathrm{CaCO}_{3}$ crystals formed were rinsed with deionized water and dehydrated through solution of ethanol in growing concentrations $(50 \%, 80 \%$ and $100 \%)$, dried at room temperature and observed the microstructure by SEM.

\section{Measurements}

For the in vitro $\mathrm{CaCO}_{3}$ crystallization, both scanning electron microscopy (SEM) and X-ray diffraction (XRD) were applied to all resultant crystals particles. The crystals were observed in a Tesla BS 343 A scanning electron microscope (SEM) and the XRD of crystals were made in Siemens D-5000X $\mathrm{X}$-ray diffractometer with $\mathrm{CuK}_{\alpha}$ radiation (graphite monochromator). The geometric scanning Bragg-Brentano $(\theta-\theta)$ and the angle range from $5^{\circ}-70^{\circ}$

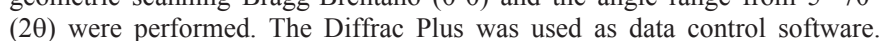
It is difficult to obtain the molecular weight of the poly(KAMPS) by GPC measurement due to the polymer aggregation on the column fillers induced by the ionic groups on the polymer side chain ${ }^{(21)}$.

\section{RESULTS AND DISCUSSION}

Poly(KAMPS) was synthesized according to the follow reaction (Scheme 1): 


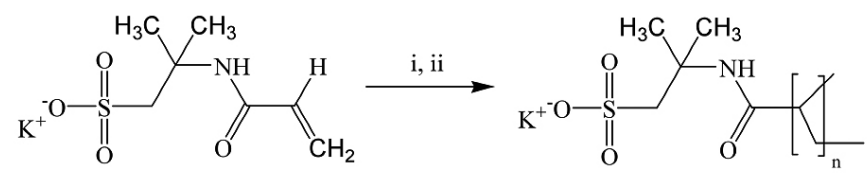

Reagent and conditions

i) 4,4'-Azobis (4-cyanovaleric acis); ACVA

ii) PVA (suspending agent) / Paraffin oil, $70^{\circ} \mathrm{C}, 4 \mathrm{~h}$

Scheme 1. Synthesis of poly(KAMPS).

Fig. 1 shows SEM images of $\mathrm{CaCO}_{3}$ crystals grown in the presence of poly(KAMPS) as additive at $1 \mathrm{mg} / \mathrm{mL}$ varying the $\mathrm{pH}$ from $\mathrm{pH} 7$ to $\mathrm{pH} 12$ at $24{ }^{\circ} \mathrm{C}$. Fig. $1 \mathrm{~A}$ shows a grouped flat $\mathrm{CaCO}_{3}$ crystals with $20 \mu \mathrm{m}$ of size with nanometric oriented triangle on the surface when $1 \mathrm{mg} / \mathrm{mL}$ of poly(KAMPS) was present at $\mathrm{pH} 7$ at $20^{\circ} \mathrm{C}$. Similarly flat shape $\mathrm{CaCO}_{3}$ morphology with poly(KAMPS) at $\mathrm{pH} \mathrm{8,9}$ and 10 were observed. Surprisingly, unusual and regular rugby-ball crystals with $10 \mu \mathrm{m}$ of size were crystalized at $\mathrm{pH}$ 7. Another observation is that the unstable polymorphism of aragonite-like crystals was also stabilized from $\mathrm{pH} 8$ to 10 (Fig. 1 B-D). Moreover, it can be seen that only oriented triangle crystals were formed from $\mathrm{pH} 7$ to 10 (Fig. 1 A-D). Fig. $1 \mathrm{E}$ shows regular aggregated rosette-like crystals of truncate calcite with size in the range of $5-10 \mu \mathrm{m}$ at $\mathrm{pH} 11$. The single calcite crystals, which are aggregated, are in the range of nanometric to micrometric in size. However, tubular calcite crystals with size in the range of 2-4 $\mu \mathrm{m}$ were obtained at $\mathrm{pH} 12$. Here we observed $\{104\}$ faces at the extreme of tubular crystals (see red arrow). At high magnification is clear to recognize the rhombohedra calcite crystals. Oriented calcite with alignment of $\{012\}$ face has been also obtained by using self-assembled monolayer (SAM) functionalized with carboxylic group using Kitano crystallization method ${ }^{(22)}$. In addition, XRD patterns of $\mathrm{CaCO}_{3}$ after crystallization using poly(KAMPS) shows $\{104\}$ face at $2 \theta=29,4^{\circ}$ as the most intense peaks confirming the calcite (data no shown). Faces of aragonite were also determined confirming the occurrence of this polymorphism at $\mathrm{pH}$ 10.
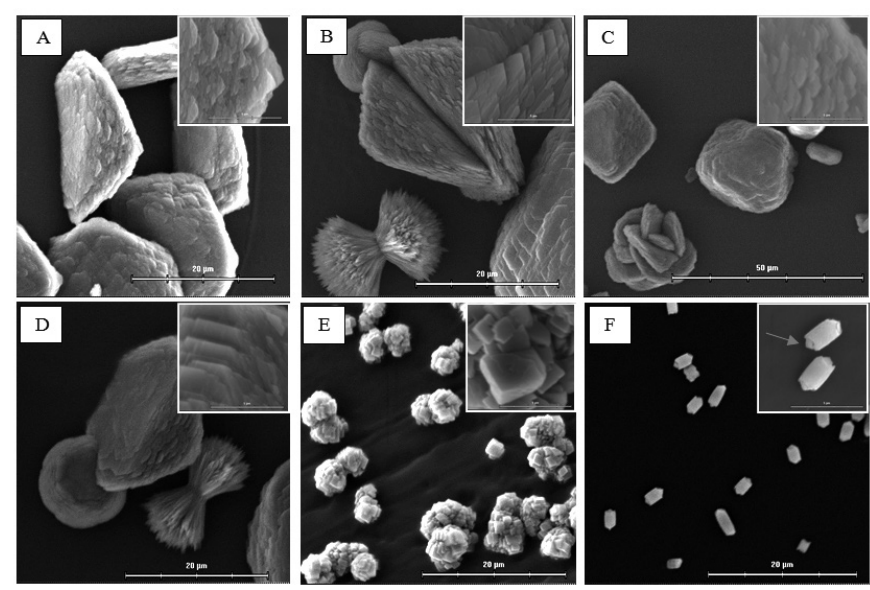

Figure 1. SEM images of $\mathrm{CaCO}_{3}$ grown using gas diffusion with $1.0 \mathrm{mg}$ / $\mathrm{mL}$ of poly(KAMPS) at different $\mathrm{pH}$ value from 7 to 12 . A) $\mathrm{pH} 7, \mathrm{~B}) \mathrm{pH} 8, \mathrm{C}$ ) $\mathrm{pH} 9$, D) $\mathrm{pH} 10, \mathrm{E}) \mathrm{pH} 11$ and $\mathrm{F}$ ) $\mathrm{pH} 12$ at $20^{\circ} \mathrm{C}$ for $24 \mathrm{~h}$.

The Fig. 2 shows a summary of the resultant oriented, aggregated of $\mathrm{CaCO}_{3}$ morphologies obtained with $1.0 \mathrm{mg} / \mathrm{mL}$ of poly(KAMPS) and their relation with the $\mathrm{pH}$ values of mineralization solution.

\section{CONCLUSIONS}

The use of poly(KAMPS) as additive template could effectively control the morphogenesis of $\mathrm{CaCO}$ crystals and its crystallographic polymorphism. The presence of sulphonate groups of poly(KAMPS) and the $\mathrm{pH}$ of the mineralization solution seem to be crucial during $\mathrm{CaCO}_{3}$ nucleation, crystal growth determining the kinetic in vitro crystallization. The $\mathrm{pH}$ of poly(KAMPS) solution can undergo different degree of sulphonic group dissociation inducing different conformation of poly(KAMPS) in solution and thereby elicit changes in $\mathrm{CaCO}_{3}$ morphology. Therefore, the resultant crystals, which is triggered by the sulphonate moieties of poly(KAMPS) results from a local accumulation of $\mathrm{Ca}^{2+}$ ions, which correlates closely with the $\mathrm{pH}$ of the mineralization solution. SEM images showed unusual $\mathrm{CaCO}_{3}$ crystal morphologies as a function of $\mathrm{pH}$, which was viable for stabilizing oriented triangle from $\mathrm{pH} 7$ to 10 and tubular shape of calcite at $\mathrm{pH} 12$, respectively. The preparation of hierarchical hollow of $\mathrm{CaCO}_{3}$ particles as inorganic complex structures have great potential in material science and anticancer therapy ${ }^{(23,24)}$. XRD pattern are in good agreement of our results demonstrated the coexistence of its polymorphs. In summary, we demonstrated that the functionalization strategy on polymers provides viable approach for studying shape, controlled morphologies and production of the unstable polymorphs of $\mathrm{CaCO}_{3}$
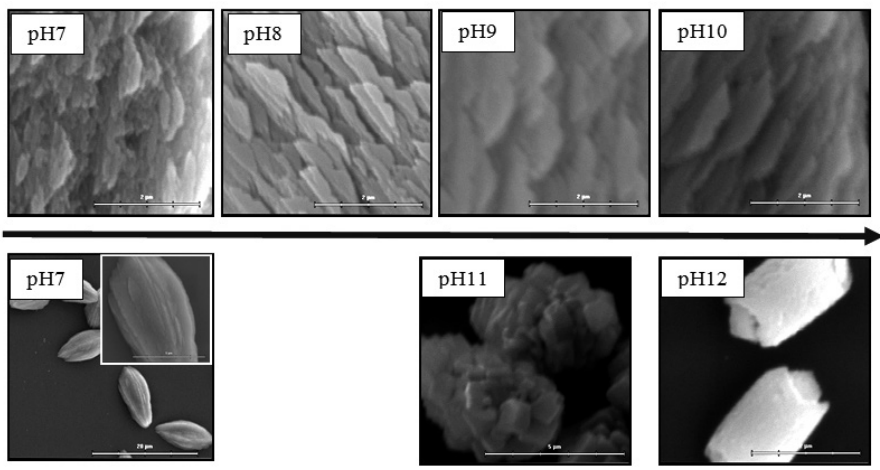

Figure 2. Scheme of oriented $\mathrm{CaCO}_{3}$ morphologies obtained with $1.0 \mathrm{mg} /$ $\mathrm{mL}$ of poly(KAMPS) at different $\mathrm{pH}$ value.

\section{ACKNOWLEDGMENTS}

This research was supported by FONDECYT 1110194 granted by the Chilean Council for Science and Technology (CONICYT).

\section{REFERENCES}

1. L. A. Lowenstam, S. Weiner, On biomineralization. Oxford University Press, New York, (1989)

2. A. V. Srinivasan, G. K. Haritos, F. L. Hedberg, Appl. Mech. Rev. 44, 463 (2004)

3. E. Bäuerlein. Biomineralization. Wiley, Weinheim, (2000)

4. S. Mann, Biomineralization, Prinziples and concepts in bioinorganic materials chemistry, Oxford University Press, (2001)

5. E. Bäuerlein, P. Behrens, M. Epple, Eds. Handbook of biomineralization. Wiley-CH, Weinheim, (2007)

6. S. Mann. Angew. Chem., Int. Ed. 39, 3392, (2000)

7. M. S. Fernández, C. Bustos, G. Luquet, D. Saez, A. Neira-Carrillo, M. Corneillat, G. Alcaraz, J. L. Arias. J. of Crustacean Biology, 32(5), 802, (2012)

8. J. L. Arias, M. S. Fernandez, A. I. Caplan, Word's Poultry Science Journal. 70, 1647, (2001)

9. H. Ehrlich. Biological Materials of Marine Origin. Springer (2010)

10. M. A. Meyers, P.Y. Chen, A. Y. M. Lin, and Y. Seki, Prog. Mater. Sci. 53, 1, (2008)

11. P.M. Dove, J.J. De Yoreo, S. Weiner (Editor). Biomineralization, Reviews in Mineralogy \& Geochemistry, Biomineralization, vol.54. (2003)

12. F.C. Meldrum, Int. Mater. Rev. 48, 187, (2003)

13. N. M. Alves, I. B. Leonor, H. S. Azevedo, R. L. Reis, J. F. Mano. J. Mater. Chem., 20, 2911, (2010)

14. C. L. Freeman, J. H. Harding, D. M. Duffy, Langmuir, 24, 9607, (2008)

15. A. Neira-Carrillo, M. Yazdani-Pedram, J. Retuert, M. Diaz-Dosque, S. Gallois, J.L. Arias. J. Colloid Interface Sci. 286, 134, (2005)

16. J. I. Arias, J. P. Wiff, M.S. Fernández, V. Fuenzalida, J.L. Arias, Mater. Res. Soc. Symp. Proc. 711, 243, (2002)

17. A. Neira-Carrillo, J. Retuert, F. Martinez, J.L. Arias. J. Chil. Chem.Soc. 53, 1367, (2008)

18. A. Neira-Carrillo, R. K. Pai, V. M. Fuenzalida, M. S. Fernández, J. Retuert, J. L. Arias, J. Chil. Chem. Soc. 53, 1469, (2008)

19. A. Neira-Carrillo, D. F. Acevedo, M.C. Miras, C. A. Barbero, D. Gebauer, H. Cölfen, J. L. Arias, Langmuir, 24, 12496, (2008)

20. A. Neira-Carrillo, P. Vásquez-Quitral, M. Paz Díaz, M. S. Fernández, J. 
L. Arias, M. Yazdani-Pedram. J. of Solid State Chem. 194, 400 (2012)

21. R. K. Pai, Synthesis and Characterization of Polymer-Mediated Biomimetic Calcium Carbonate Materials. Ph.D. Dissertation, University of Ulm, Germany, (2005)
22. A. M. Travaille, L. Kaptijn, P. Verwer, B. Hulsken, J. A. A. W. Elemans, R. J. M. Nolte, H. van Kempen, J. Am. Chem. Soc. 125, 11571 (2003)

23. R. K. Pai, S. Pillai, Cryst Growth Des, 7, 215 (2007)

24. W. Wei, G.-H. Ma, G. Hu, D. Yu, T. Mcleish, Z.-G. Su, Z.-Y. Shen, J. Am. Chem. Soc., 130, 15808, (2008) 